\title{
How to succeed with volunteers on the basis of commitment and ownership
}

\author{
Andreas Wæhle ${ }^{1}$, Nora Rogne ${ }^{2}$, Stian Westbye ${ }^{2}$, \\ Jørgen Nilsen ${ }^{1}$, Sigurd Tollevik ${ }^{1}$ and Kjell G. Robbersmyr ${ }^{1}$ \\ ${ }^{1}$ Department of Engineering Sciences, University of Agder, Norway \\ ${ }^{2}$ School of Business and Law, University of Agder, Norway
}

\begin{abstract}
:
Organising a multidisciplinary student organisation face challenges in regards to student engagement, ownership and commitment. This article will discuss key factors to create commitment and ownership in volunteer organisations. The identified factors are 1) an engaged core group of ambassadors who spread motivation, passion and drive, 2) build relations across departments and level of responsibility to lower the threshold to share ideas, give feedback and ask for advice, 3) expedient and communicated organisational structure that divides responsibility and ensures collaboration, and 4) clear individual and personal incentive to participate. These factors will increase your likelihood of success with motivating your members to be committed and take ownership.
\end{abstract}

Align Racing UiA, the case of this study, is a student organisation with over 60 students engaged in multidisciplinary tasks. The team goal is to produce one race car per year and compete in Formula Student. The core visions for the team was establishment of community spirit, ownership and commonly established success factors. This vision, and continuous progress, was enacted throughout the year of the competition with a focus on dependable communication across the departments and fast paced problem solving. The team achievements were impressive, compared with other Formula Student teams.

Key words: Student organisation, Multi-disciplinary project, Student engagement, Voluntary work, Formula Student

\section{INTRODUCTION}

Building a student organisation is challenging, particularly the aspect of how to organise and motivate members. Align Racing UiA (AR) is a Formula Student (FS) team at the University of Agder (UiA) that consists of over 60 students from different disciplines, working voluntarily to achieve the team goal competing with their race car at Silverstone Race Circuit, UK. FS is one of the largest student competitions in the world, giving teams the objective of being a real firm and producing a prototype race car [1]. The vision for AR is to create an A-team and a B-car. More specifically, focusing on making a successful team, where members are challenged, supported and thrive. The car becomes the product of team spirit, collaboration and passion.

The rulebook of FS is complex and detailed. However, it does not dictate how to organise a voluntary organisation and motivate students in a complex multidisciplinary project. Additionally, the challenge of balancing demand for studies and FS contribution. These challenges are faced by, but not limited to, voluntary student organisations and will be addressed and reflected upon based on more than two years of experience from leading AR. Therefore, the question is: What are the key factors to gain commitment and ownership from members in student organisations? 


\section{BACKGROUND}

As a result of the intricacy of the competition, AR had several obstacles to overcome. Firstly, members had scarce to none preliminary knowledge in complex project engagement, conflict of interest nor being part of an organisation. Secondly, leaders had limited experience in project development, leadership and/or conflict resolution. Lastly, designing and building a competitive race car from scratch in less than nine months. As a result, an arena for trial and error emerged and an agile development approach to the project was introduced. Based on the continuous acquisition of knowledge and experience, processes in the above-mentioned areas were enhanced throughout the first year for AR.

The organisation was structured with a decentralized management, by having financial, marketing, Human Resources (HR), and the technical department in four sub-groups to secure member autonomy. In addition, the board consists of all department leaders. This is illustrated in figure 1.

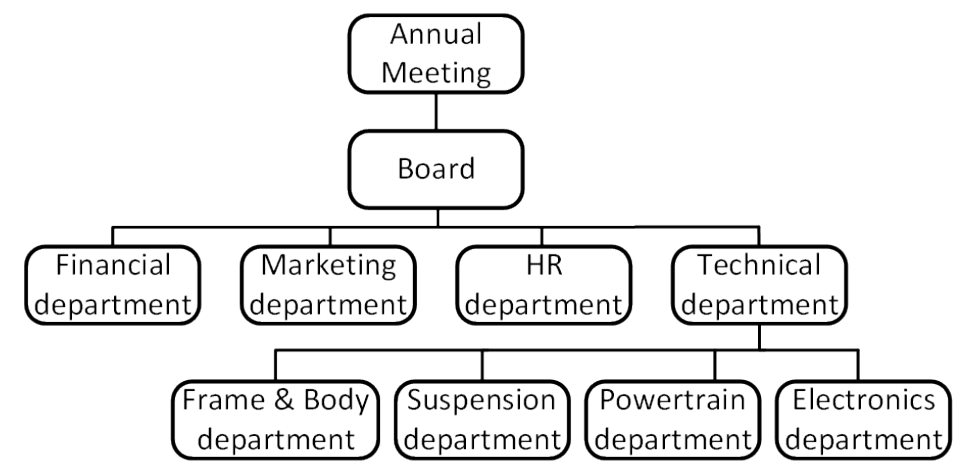

Figure 1: Align Racing 2018-2019 Organisation Structure

The structure was functionally dividing the departments to clarify areas of responsibility, establish interactions and a community inside and between departments. Furthermore, the communication channels ensured information flow, built ownership and shared member's achievements, which actively assembles a team [2]. One such important channel was meetings. They kept the team updated, coordinated and connected, and sought to engage and gather the team towards the main goal. All meetings had different approaches and intentions. Weekly team meetings focused on department progress updates, challenges and achievements. Department meetings aimed to solve challenges and coordinate work and support. And lastly board meetings discussed organisational strategy, project management and how to solve internal and external conflicts. Regardless of structure and topics, all meetings intended to unify and engage the team.

\section{MOTIVATING STUDENTS TO GET ENGAGED IN VOLUNTARY WORK}

As mentioned above, leaders had little to none preliminary leadership experience and their main challenge was to motivate all members to take responsibility, be present and engage. However, what motivates individuals differ. Study shows that many students seek more relevant experience, since their personal desires will not be satisfied by only attending lectures with low class interaction [3]. Therefore, their personal desires might be fueled by a motivation to stand out from the crowd of jobseekers. Furthermore, students who engage in extracurricular activities can outperform the students who mainly attend classes [4]. A study also refers to the fact that student organisations emerge because of the students' pursuit of growth [3]. Furthermore, the motivation of learning and career opportunities is one of the reasons people engage [5]. This was the main motivation for establishing AR - namely to provide a unique offer where students can put theory into practice.

Even though the offer is extraordinary compared to other student organisations at UiA, there are still challenges related to getting students engaged in voluntary work. On one hand, the project was, and still is, a complex and time consuming project. The students are intimidated by the size of the project, and consider their spare time as too valuable. On the other hand, there are different factors motivating students to get engaged in voluntary organisations. Only two other universities in Norway offer similar exclusive projects, which may be a motivational factor to join. Based on experience and reflections, 
members of AR can be categorised into three different segments dependent on their project commitment and ownership. These are a) ambassadors, b) opportunity-seekers and c) free-riders.

(a) Ambassadors: Students who constitute the core, but minor part of the team. They get motivated by the total value of the project and by seeing the motivation of the other members. They are engaged in many areas of the project, also outside their own areas of expertise. Additionally, they find joy in collaboration and facilitating for the team goal. The ambassadors have a unique ability to inspire both the opportunity-seekers and the free-riders to engage on a higher level, with their passion and capability to influence, motivate and include. This group has a high level of commitment and ownership.

(b) Opportunity-seekers: Students who engage to gain new interdisciplinary networks with other students and hands-on experience in a unique learning arena. This segment of students forms the majority of the recruited group. They are keen to be part of a unity and to see the results of their work. They get motivated by the opportunity to be creative, the possibility to try and fail and also by getting an extraordinary team feeling. Still, the opportunity-seekers have a lower level of commitment and ownership than the ambassadors.

(c) Free-riders: Students who only get engaged by having something to put on their resume, without taking a noticeable part of the project or the team. This group forms a smaller part of the team and may not see the total value of the project. They nearly engage to get a certain kind of experience, but have a low degree of both commitment and ownership. These are mainly selected out during the recruitment process.

Figure 2 illustrates the degree of commitment and ownership of the ambassadors (a), opportunity-seekers (b) and free-riders (c). What summarises the different segments above, is that different factors affect the individual motivation to engage. Their individual motivation affects the degree of commitment and ownership, and will likely influence the project progress and success.

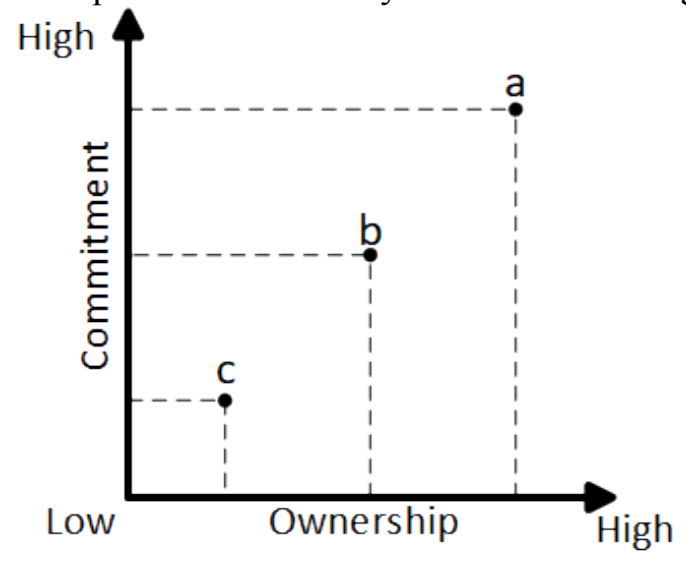

Figure 2: The degree of commitment and ownership in student organizations

\section{FORMAL AND INFORMAL LEADERS APPROACHES TO MOTIVATE MEMBERS}

Formal leaders have to visualise and communicate the benefits of participating in the project [6]. At the same time, goals should be determined in collaboration with all affected members [2]. This provides an opportunity to influence team goals, which can accelerate member's ownership to goals and increase their motivation to perform. Hence, leaders explicitly illustrate that members' opinion counts and their trust in them.

Informal leaders are as important as formal leaders. While formal leaders have a role in the organisation to secure progress, engagement and strategy to reach goals, the ambassadors have an essential role to build the culture as informal leaders. They take extra responsibility and have a particularly important responsibility as role models for other members and casual sparring partners. Research shows that this is a normal effect of ownership that is unique for nonprofit organisations [7-9]. In AR the ambassadors had a huge impact by lowering the threshold for asking questions, creating unity, and also by both including opportunity-seekers and engaging free-riders. Thus, they built a safe learning environment where challenges are solved in cooperation.

As everyone else, ambassadors also need to be motivated. Therefore, formal leaders need to appreciate and recognise their work and encourage ambassadors to continue spreading their passion and drive. By doing so, ambassadors are more likely to take more responsibility both for challenging tasks and also 
other members' wellbeing. With support from informal motivators, members are likely to feel seen and included, which impacts their probability to thrive, commit and find motivation to participate [2]. Hence, free-riders can be turned into opportunity seekers or even to ambassadors by igniting their passion.

However, regardless of how much formal leaders, ambassadors and members try to engage and motivate, some will never participate. If this attitude is to be accepted and if they definitely are not willing to collaborate, it might influence others efforts negatively. How these situations are handled, is crucial. In our experience, the best solution is to talk and listen to them to discover the core reason for their lacking interest. Generally members have their reasons, upon which it should be decided together what the best action is, either leave the team freely or be given a new chance. How these situations are handled impacts stakeholders' impression of the organisation.

\section{STRUCTURE AND CLEAR RESPONSIBILITIES}

The fundament for student organisations can not only be built on members motivation alone. The engagement will vary from year to year based on the team composition, goals and level of challenges. Student organisations have a naturally high level of turnover caused by graduation. Therefore, a solid organisation structure with established frames are key for easy transition to the next team. A lot of information and experience are preserved in organisation structures, processes and procedures. In the first year, a standard organisational structure was created and adjusted throughout the year, as illustrated in Figure 1. Further on, the technical department changed to a matrix structure to assure better processes for knowledge sharing. The structure separated functions, united the organisation and coordinated our members. In practise, the boundaries between departments were small and members worked across disciplines and shared knowledge. Still, the connection to "their own" department was important to gain confidence, commitment and a feeling of belonging.

The organisational structure is not only creating an understanding of the organisation and its departments, it also divides the responsibility between members. The members have their own area of responsibility which provides role clarification. In addition, role clarification built commitment and ownership to tasks. By dividing the responsibility, the members were able to work autonomously and cross-functionally. Also, shared responsibility and involvement can enhance volunteer motivation [2]. Therefore, members were able to dig deep into specific challenges, and also know who to contact and discuss solutions with. Here the magic of collaboration, ownership and coordination evolved itself.

\section{BUILDING RELATIONS INSIDE AND ACROSS TEAMS}

In addition to the formal structure, the power of social relations inside and across departments unveiled itself during the project. Members got to know each other and built friendships, which influences volunteers' commitment and engagement [10]. The social aspect is perhaps the most critical element in creating a united community, because it contributes to develop solidarity, which gives members a sense of belonging. Cross-functional relations clearly impacted members motivation, coordination and time spent on the project. Members felt more comfortable to ask for help, discuss challenges and share ideas, which improved the quality of the project. These social relations were built on different arenas, such as meetings, small talk, social parties and smaller cross-functional collaborations. Members were "forced" to work together and gained respect for others' work, regardless of which department they belonged to.

Furthermore, social relations made members care about each other, which resulted in some free-riders turning into opportunity-seekers. Further enhancement of motivation derived from evident care outside the project. At Silverstone Circuit it showed that creating an organisational structure and strong relations, which focused on cross-disciplinary strengths, was a great return of investment. This resulted in 3rd place in marketing for both competition years, the award "Best Newcomer" 1 st competition year, and 13th place overall of 81 teams for 2 nd competition year.

\section{CONCLUSION}

In student organisations, the motivational factors for members should be clear and explicitly communicated with accompanied goals. Additionally, building relations and friendships across studies and interests, being part of a skilled team and getting real work experience are all motivational factors for the members. In addition, volunteer projects require a huge amount of time, focus and effort to reach the 
team goal. AR became a lifestyle - an identity, not just a project. By facilitating such a project, one will ensure that the university educates qualified and experienced students, hence make them attractive for future employers. This was, and still is, the basic idea of the organisation today, where the focus is on forming an A-team and a B-car. With this as a starting point, it was crucial for formal leaders to create commitment and ownership, as they will face all the challenges related to leadership of all segments of volunteer students. Based on our experience and reflections, we have four recommendations for future volunteer organisations and its leadership. These four factors are vital to gain ownership and commitment, and are prioritised by order:

1. An engaged core group of ambassadors who spread motivation, passion and drive

2. Build relations across departments and level of responsibility to lower the threshold to share ideas, give feedback and ask for advice

3. Expedient and communicated organisation structure, which divide area of responsibility and unite the team

4. Clear individual and personal incentive to participate

\section{REFERENCES}

[1] IMechE. (2021). "Formula Student," [Online]. Available: https://www . imeche .org/events/ formula-student/about-formula-student (visited on 09/01/2021).

[2] Ainsworth, J., "Feelings of ownership and volunteering: Examining psychological ownership as a volunteering motivation for nonprofit service organisations," Journal of Retailing and Consumer Services, vol. 52, pp. 1-8, 2020. [Online]. Available: https : / / doi . org/10 . 1016/ j.jretconser.2019.101931.

[3] Borges, J. C., Cezarino, L. O., Ferreira, T. C., Sala, O. T. M., Unglaub, D. L., and Caldana, A. C. F., "Student organizations and communities of practice: Actions for the 2030 agenda for sustainable development.," The International Journal of Management Education, vol. 15, no. 2, pp. 172-182, 2017.

[4] Baker, C., "Under-represented college students and extracurricular involvement: The effects of various student organizations on academic performance.," Social Psychology of Education, vol. 11, no. 3, pp. 273-298, 2008. [Online]. Available: https : //doi .org/10 . 1007/s11218-0079050-y.

[5] Clary, E., Snyder, M., Ridge, R., Copeland, J., Stukas, A., Haugen, J., and Miene, P., "Understanding and assessing the motivations of volunteers: A functional approach," Journal of Personality and Social Psychology, vol. 74, no. 6, 1998.

[6] Dwyer, P., Bono, J., Snyder, M., Nov, O., and Berson, Y., "Sources of volunteer motivation: Transformational leadership and personal motives influence volunteer outcomes," Nonprofit Management and Leadership and Personal Motives Influence Volunteer Outcomes, vol. 24, no. 2, pp. 181205, 2013. [Online]. Available: https://doi .org/10.1002/nml. 21084.

[7] Pierce, J., Kostova, T., and Dirks, K., "Toward a theory of psychological ownership in organizations," The Academy of Management Review, vol. 26, no. 2, pp. 298-310, 2001. [Online]. Available: https://doi.org/10.2307/259124.

[8] Van Dyne, L., Cummings, L. L., and McLean Parks, J., "Extra-role behaviors: In pursuit of construct and definitional clarity," Research in Organizational Behavior: an annual series of analytical essays and critical reviews, vol. 17, pp. 215-285, 1995.

[9] Vandewalle, D., Van Dyne, L., and Kostova, T., "Psychological ownership: An empirical examination of its consequences," Consequences. Group \& Organization Management, vol. 20, no. 2, pp. 210-226, 1995. [Online]. Available: https://doi.org/10.1177/1059601195202008.

[10] Farmer, S. M. and Fedor, D. B., "Changing the focus on volunteering: An investigation of volunteers' multiple contributions to a charitable organization," Journal of Management, vol. 27, no. 2, pp. 191-211, 2017. [Online]. Available: https : / / doi .org/10 . 1016 / S0149-2063(00) 00095-7. 